\title{
HISTÓRIA DA GEOGRAFIA AGRÁRIA BRASILEIRA: Pierre Monbeig e Leo Waibel
}

\author{
history of brazilian agrarian geography: Pierre Monbeig and Leo Waibel
}

\author{
Flamarion Dutra Alves*
}

Enéas Rente Ferreira**

\section{Resumo}

Este artigo tem como objetivo discutir algumas contribuições herdadas dos geógrafos alemães e franceses na geografia agrária brasileira. Entre essas contribuições, destacam-se as questões metodológicas, teóricas e técnicas de pesquisa. O período analisado começa na década de 1930, período que marcou o surgimento da geografia acadêmica e científica no Brasil, o qual se centra nos estudos dos geógrafos Pierre Monbeig e Leo Waibel. Dessa forma, este artigo busca resgatar a memória da geografia brasileira, em especial a geografia agrária.

Palavras-chave: Metodologia, Pierre Monbeig, Leo Waibel, teorias, história do pensamento geográfico.

\section{Abstract}

This paper aims at discussing some contributions made by the German and French geographers to Brazilian agrarian geography. Among these contributions dominate the ones on methodological, theoretical and technical research issues. The analyzed period begins in the 1930s, a period which signed the emergence of the academic and scientific geography in Brazil. This essay focuses on the studies of the geographers Pierre Monbeig and Leo Waibel. Thus, this paper aims at recovering Brazilian's geography memory, especially the agrarian geography.

Key words:Methodology, Pierre Monbeig, Leo Waibel, theories, history of geographical thinking.

\section{Résumé}

Cet essai a pour objectif de discuter quelques contributions faites par les géographes allemands et français à la géographie agraire brésilienne. Parmi ces contributions dominent les questions méthodologiques, théoriques et techniques de la recherche. La période analysée commence dans les années1930, qui a marqué l'émergence de la géographie académique. Ce travail focalise sur les études des géographes Pierre Monbeig et Leo Waibel. Cet essai propose donc d'aider à préserver la mémoire géographique brésilienne, en particulier, la géographie agraire.

Mots clé: Méthodologie, Pierre Monbeig, Leo Waibel, théories, histoire de la pensée géographique.

(*) Prof. Dr. da Universidade Federal de Alfenas, Curso de Geografia - Rua Gabriel Monteiro da Silva, 700. Bairro Centro CEP. 37130-000, Alfenas (MG) - Brasil, Tel.: (+ 55 35) 3299.1449 - dutrasm@yahoo.com.br

(**) Prof. Dr. do Programa de Pós-Graduação em Geografia da Universidade Estadual Paulista Júlio de Mesquita Filho/ - Av 24A n ${ }^{\circ}$ 1515, Jardim Bela Vista, CEP: 13.506-900 - Rio Claro (SP) - Brasil, Tel: (+ 55 19) 35269226 - eneasrf@rc.unesp.br 
ALVES, F. D.; FERREIRA, E. R.

\section{INTRODUÇÃO}

O objetivo central deste artigo é fazer uma retrospectiva dos principais autores que contribuíram para a construção da geografia agrária brasileira, sendo eles geógrafos ou cientistas de outras áreas do conhecimento. Nesta investigação, as análises estarão focadas em dois geógrafos que ajudaram a fundar a geografia agrária no Brasil, o francês Pierre Monbeig e o alemão Leo Waibel.

Dessa forma, esse trabalho dará início à série de artigos que visam resgatar a memória e o pensamento da geografia agrária brasileira, mostrando um pouco da biografia dos autores, seus fundamentos teórico-metodológicos, temáticas estudadas e técnicas de pesquisas utilizadas, a fim de entender a evolução/transformação do pensamento agrária na ciência geográfica.

\section{GEOGRAFIA UNIVERSITÁRIA NO BRASIL}

A geografia universitária brasileira surgiu na década de 1930, com a vinda de geógrafos franceses para criarem os cursos de geografia em São Paulo e Rio de Janeiro, 1934 e 1935 respectivamente. Durante a mesma década, foram criados outros órgãos ligados à ciência geográfica que fundaram definitivamente a geografia brasileira, como, em 1933, a criação do Conselho Nacional de Geografia (CNG), em 1934, a criação da Associação dos Geógrafos Brasileiros (AGB), fundada por Pierre Deffontaines e, no ano de 1938, o Instituto Brasileiro de Geografia e Estatística (IBGE).

A geografia agrária, assim como a geografia humana como um todo, esteve embasada nos pressupostos metodológicos franceses ligados aos estudos regionais de Paul Vidal de La Blache e Albert Demangeon, que estimularam vários geógrafos, dentre eles Pierre Monbeig, Pierre Deffontaines, Francis Ruellan e outros.

Os pressupostos teóricos alemães influenciaram com intensidade menor a geografia brasileira, pode-se citar a geopolítica de Friedrich Ratzel que serviu de base nos estudos de Everardo Backheuser, que foi um dos influentes na criação do IBGE. Outro geógrafo alemão com destaque no Brasil é Leo Waibel, trazido ao país a cargo do Conselho Nacional de Geografia, para realização de estudos nas frentes pioneiras. Formou diversos discípulos, entre eles Orlando Valverde.

Nas décadas de 1940 e 1950, os maiores expoentes da geografia agrária e dos estudos humanos foram Pasquale Petrone, Ary França, Nilo Bernardes e Lysia Bernardes, que tiveram na vertente francesa a fonte de suas pesquisas geográficas. Orlando Valverde e Leo Waibel foram os mais renomados geógrafos que seguiram as linhas gerais do pensamento geográfico alemão.

Nesse sentido, o artigo tentará mostrar de forma sintética alguns pontos da influência francesa e alemã no Brasil, analisando a obra de Pierre Monbeig e Leo Waibel, no que tange a metodologia, as técnicas, o uso de teorias e conceitos, e de que forma estes pressupostos teórico-metodológicos contribuíram para a geografia agrária brasileira.

\section{PIERRE MONBEIG: Pressupostos teórico-metodológicos franceses e a contribuição à geografia agrária brasileira}

Um dos maiores nomes na geografia agrária brasileira foi, sem dúvida, Pierre Monbeig (Foto 1), discípulo de Albert Demangeon. Ele se inspirou nas bases metodológicas sistematizadas por Paul Vidal de La Blache e desenvolveu, no Brasil, seus mais importantes trabalhos geográficos.

Pierre Monbeig (1908-1987) esteve no Brasil de 1935 a 1946, na fundação do curso de geografia na Universidade de São Paulo. Durante este período, publicou diversos artigos nos periódicos de geografia e dois livros, "Ensaios de Geografia Humana Brasileira" (1940) e "La crise des sciences de l'Homme"(1943). Após sua volta à França, publicou mais quatro livros "Novos Estudos de Geografia Humana Brasileira", "Le Brésil", "La Croissance de la ville de São Paulo" e "Pioneiros e Fazendeiros de São Paulo". Este último livro foi resultado de sua tese de doutorado defendida e premiada na Sorbonne, no ano de 1950. 


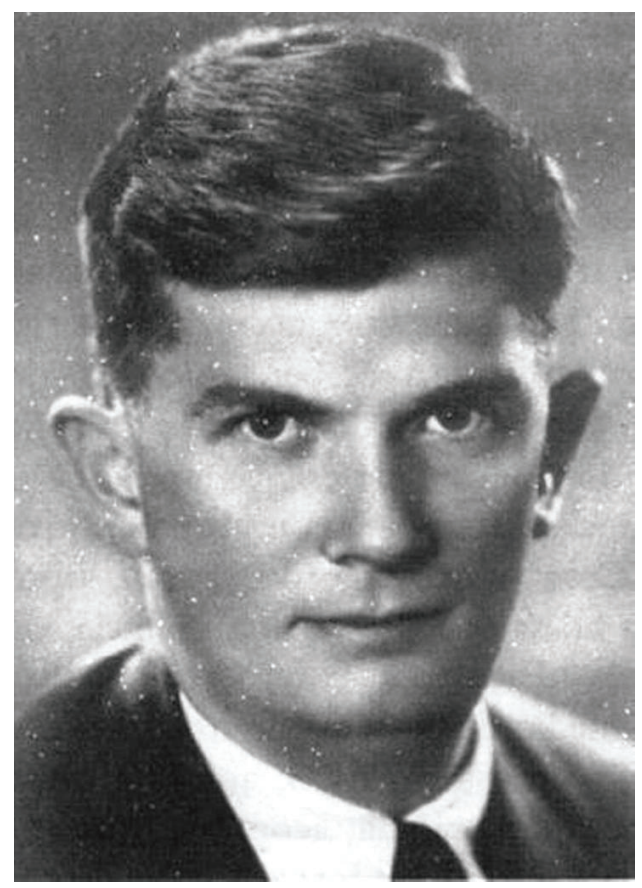

Foto 1 - Pierre Monbeig Fonte: AB'SÁBER (1994)

Em sua metodologia, ressaltam-se os estudos regionais e monográficos, oriundos dos intensos e bem descritos trabalhos de campo:

A prática vidaliana de trabalho de campo e a incorporação em suas pesquisas mostram muito bem como o "terrain", em certa medida, substitui o livro, o texto e, até mesmo, o arquivo histórico. Ele adquire um valor heurístico fundamental, visto que constitui o substrato no qual se lê a relação homem/meio, que se torna, a partir do início do século XX, a problemática explícita da geografia humana francesa. (DANTAS, 2005, p.26).

Silvio Bray $(1980,1987,2008)$ entende que Pierre Monbeig desenvolveu seus trabalhos no Brasil sob a ótica do positivismo-funcionalista-culturalista. A respeito do funcionalismo na geografia brasileira, ele exemplifica sobre este método de pesquisa:

Na geografia brasileira, a interpretação funcionalista normalmente apresentou-se sensível aos problemas geográficos de mudança no espaço, como é o exemplo do trabalho clássico de Monbeig (1952) "Pionniers et Planteurs de São Paulo". Essa preocupação com a dinâmica espacial e os arranjos da "fisiologia das paisagens" e das "alterações" e " persistências" dos elementos geográficos tem sido utilizada para explicar as organizações atuais, através de um perspectiva pluricausal. (BRAY, 1980, p.40).

Com relação à perspectiva positivista-funcionalista-culturalista, entende-se que foi Positivista, pois se atentou à observação e aos fatos concretos, e não aos abstratos, com ênfase o empírico. A questão Funcionalista no seu método abarca elementos da sociedade, sobre os quais exercem funções sociais que determinam correlações diretas e indiretas, numa abordagem sistêmica do espaço. Assim, essa relação estaria em constante harmonia e conformidade. E por último, a perspectiva Culturalista que valoriza os aspectos humanos, na sua organização, modos e gêneros de vida.

Esse conjunto de perspectivas acadêmicas trabalhadas por Pierre Monbeig aprimorou o conceito utilizado por ele na explicação dos fatos geográficos, ou seja, a noção de Complexo Geográfico:

Monbeig desenvolveu o complexo geográfico como um sistema funcional-estrutural. O sistema funcional-estrutural da escola francesa de geografia positivista funcionalista-culturalista, tem por 
base o sistema biológico. No sistema biológico-organicista, o todo orgânico encontra-se regido pelas diferentes funções das diferentes partes. Portanto, a noção de sistema funcional-estrutural na geografia funcionalista-culturalista tem como paradigma o modelo biológico. Mas, queremos salientar, que a geografia não utiliza o modelo biológico como analogia - pois os fatos geográficos são diferentes dos fatos biológicos - e sim, utiliza-o como referência. (BRAY, 2008, p.4).

A relação do meio físico com os elementos humanos são exaltados na obra de Monbeig, ele não dissocia os impactos e as dinâmicas do domínio físico sobre o homem, entretanto, essas são condições que alteram os modos de vida das populações. Porém, não é determinante quanto à sua vivência, apenas devem ser considerados para entender determinadas situações daquele modo de vida existente.

Ainda sobre a questão metodológica de Pierre Monbeig, Bray (1987) faz uma análise das obras e do método de pesquisa:

A obra mais expressiva quanto ao seu método de investigação e de interpretação é "Pioneiros e fazendeiros de São Paulo". Entretanto, o livro mais significativo quanto às suas idéias geográficas e à sua visão de mundo, encontra-se em "Novos estudos de geografia humana brasileira", contendo coletânea de expressivos artigos publicados em periódicos nacionais, nas décadas de 30,40 e 50 . (BRAY, 1987, p.120).

As obras de Pierre Monbeig destacaram a importância do trabalho de campo na geografia, ressaltando os aspectos observáveis e vividos pelo geógrafo na prática empírica. Essas características são fundamentais para Monbeig na compreensão dos modos e gêneros de vida, elementos básicos da geografia regional francesa.

As temáticas analisadas por Pierre Monbeig perpassam por vários assuntos da geografia humana. Salientamos, na geografia agrária, a expansão cafeeira no interior de São Paulo e Paraná e sua correlação com a construção de ferrovias e cidades ao longo desse front. Assim também, destacam-se temas ligados aos gêneros de vida de diferentes regiões analisadas em suas pesquisas quando ele esteve no Brasil, tratando principalmente do habitat rural, conceito muito utilizado entre as décadas de 1930 a 1960, devido à forte influência lablachiana.

A abordagem histórica foi bastante trabalha por Pierre Monbeig, na questão dos estudos regionais. Sobre isso, ele faz algumas observações a respeito dos métodos científicos nos estudos geográficos, lembrando-se do método histórico "Basta citar a obra de Vidal de La Blache e seus discípulos para avaliar-se o papel essencial que o espírito e o método histórico devem desempenhar nos estudos e pesquisas geográficas" (1944, p.9). O autor ao tratar a inter-relação da geografia humana e a história cita Albert Demangeon "a geografia humana estuda as relações entre as sociedades humanas e o meio no presente e no passado" (1944a, p.9). Ainda nos lastros teóricos de Pierre Monbeig, menciona-se o trabalho de Georges para exemplificar o método da Geografia Humana:

É preciso simplesmente procurar explicar o gênero de vida atual analisando seus elementos à luz do método histórico que é o único a fazer compreender o lugar que ocupam hoje [...] o estudo de um gênero de vida é a aplicação de método histórico à atualidade regional (MONBEIG, 1944a, p.10).

O autor ainda alerta para o uso indevido do método histórico nas pesquisas geográficas:

A interpretação da história e da geografia é, pois, geral e constante, uma pesquisa de geografia humana não tendo senão um resultado incompleto e um valor científico limitado se aquele que a realiza não tem, além do espírito geográfico, uma mentalidade histórica. (MONBEIG, 1944a, p.10).

Baseado em Demangeon, Pierre Monbeig (1945c, p.165-166) destaca três pilares metodológicos da geografia, "o primeiro é que a geografia localiza [...] em segundo lugar, a geografia descreve [...] depois de ter localizado, depois de ter descrito, o geógrafo compara", ou seja, a ferramenta principal 
do geógrafo é a observação, na qual ele realiza um processo de descrição do que ele vê e, a partir disso, faz relações com outras paisagens ou elementos (figura 2).

ENFOQUES METODOLÓGICOS EM GEOGRAFIA HUMANA (Delgado de Carvalho e Pereira)

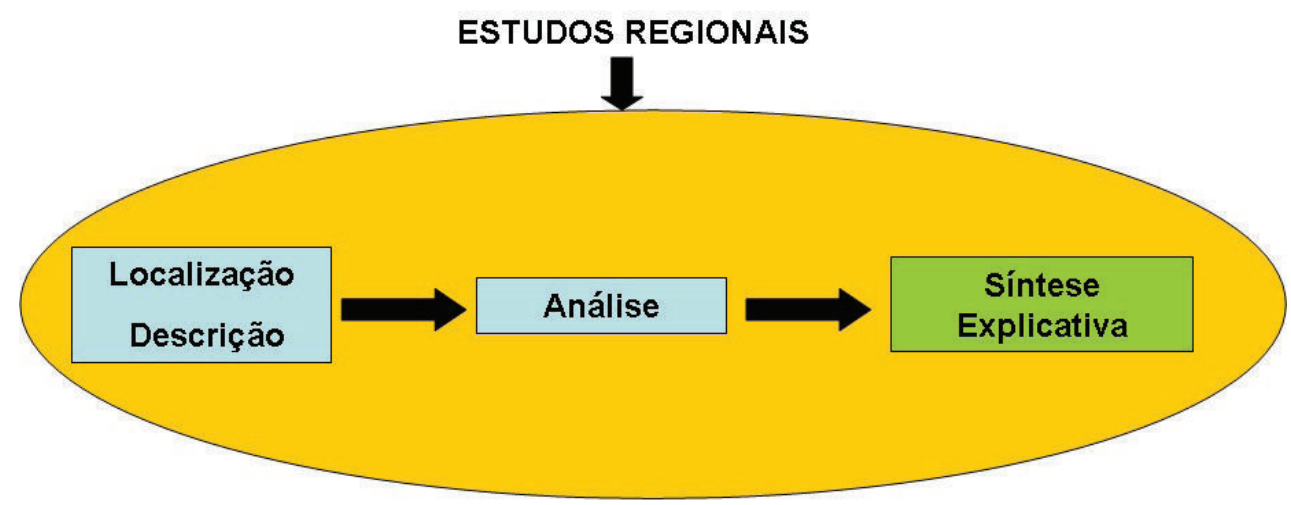

Figura 2 - Organograma 1: Síntese metodológica do geógrafo clássico, conforme Monbeig e Demangeon. Fonte: ALVES e FERREIRA (2008, p.55).

Diferentemente da síntese explicativa da região, Monbeig e Demangeon conferem uma análise comparativa entre diferentes regiões, possibilitando um conhecimento maior das realidades. Sobre esse procedimento metodológico Monbeig (1945c, p.166) ainda diz que "o método comparativo ajuda ao mesmo tempo a fazer perceber aos jovens espíritos a transformação perpétua das coisas e das sociedades humanas". Ele ressalta que, para fazer tais comparações, o geógrafo deve desenvolver a capacidade de observar:

[...] sem exagero, que a geografia é a arte de saber ver: saber ver a paisagem, saber ver um mapa, uma fotografia. Esse estudo analítico das paisagens ou de suas reproduções, que é feito por uma leitura atenciosa e precisa, constitui um excelente exercício de observação [...] a observação é a fase inicial da descrição e isso conduz a uma reflexão sistematizada. (1945c, p.166).

Após as duas etapas iniciais, o geógrafo se depara com a análise comparativa. A respeito desse método, Monbeig (1945c) afirma que "a utilização do método comparativo permitirá assinalar que existem casos análogos, mas nunca casos perfeitamente idênticos. Imediatamente, aparecerá a idéia da multiplicidade das causas tanto quanto de seus efeitos", ou seja, a comparação serve como uma ferramenta para desenvolver ideias em regiões, paisagens ou estudos conhecidos.

Pierre Monbeig reafirma a importância dos estudos regionais para a geografia a fim de conhecer e compreender a realidade:

É, entretanto no quadro da região que melhor se entra em contato com a realidade: a complexidade das relações entre os grupos humanos e as condições naturais aparece em maior destaque que em golpes de vista de conjunto. O estudo é essencialmente analítico, tratando sucessivamente dos diferentes aspectos físicos e depois dos fatos humanos; não se limita a uma descrição seca e não exclui uma conclusão onde for possível trazer a luz o ajustamento ou, ao contrário, o desajustamento entre as condições geográficas permanentes e o estado atual das atividades humanas. (MONBEIG, 1945d, p.915).

Essa abordagem regional, através do método indutivo, é latente nas pesquisas da geografia clássica ou tradicional. Sobre as questões metodológicas da geografia humana, Monbeig (1946) define o padrão metódico da escola clássica: 
[...] os estudos clássicos de Geografia não deixam nunca de descrever o habitat e a vida rural e, entretanto, não dedicam, e raramente, mais do que algumas pobres linhas à alimentação. Lacuna incompreensível. Talvez porque aos geógrafos faltasse ainda um método capaz de orientá-los nesse domínio; perceberam o perigo de penetrar nos domínios dos folcloristas ou dos higienistas. (MONBEIG, 1946,p.1268).

Nesse trabalho, Monbeig mostrou algumas fragilidades do método indutivo, na qual há pouco ou nenhum interesse em estudar a questão alimentícia da população.

Analisando essas considerações sobre os aspectos teórico-metodológicos de Pierre Monbeig, colocamos a observação de Dantas (2002) a respeito do pensamento conjuntivo desse geógrafo:

É uma Geografia com determinações variadas, na qual os diversos elementos devem ser analisados e compreendidos no contexto de que fazem parte, o que quer dizer que um mesmo elemento pode influenciar a configuração espacial de forma diferenciada, a depender das circunstâncias em que se encontra e de onde se encontra. (DANTAS, 2002, p.76).

\section{Temas estudados por Pierre Monbeig}

Várias pesquisas desenvolvidas por Pierre Monbeig foram publicadas no Boletim Geográfico que mostraram os principais assuntos da produção científica do geógrafo francês. A maioria deles retrata a fase descritiva da geografia agrária brasileira. Nesse periódico, Monbeig (1944b) revela a evolução da paisagem rural no estado de São Paulo, considerando os aspectos físicos como moldadores da paisagem, mas também destaca a importância da imigração europeia para a modificação da paisagem do interior paulista:

Mas seria um erro querer a todo custo encontrar nos fenômenos atmosféricos a única explicação da paisagem rural atual. Apesar das frentes de povoamento paulista estarem em pleno desenvolvimento, apesar do observador notar muitas marcas de juventude, não se pode esquecer que este país jovem é explorado e, em parte, explorado há mais de quatro séculos. (MONBEIG, 1944b, p. 428).

Fica claro que o aspecto culturalista e a busca pelo entendimento das regiões culturais é uma marca na trajetória científica de Monbeig. Como característica acentuada dessa fase na geografia rural, são apresentadas definições dos gêneros de vida e dos habitat rurais. Monbeig (1944b) mostra os gêneros de vida das populações no interior paulista:

[...] para descrever os caipiras de São José dos Campos que só sabiam cultivar o solo pela enxada e pelo fogo, para produzir o pouco de milho, de arroz e de feijão necessário à sua subsistência. As reações psicológicas de nosso viajante tem o grande interesse de precisar os dois gêneros de vida tão fortemente opostos, um pelo seu nomadismo e pela pobreza de sua técnica agrícola, a outra, ao contrário, por sua vida sedentária e seu caráter semi-industrial. (MONBEIG, 1944b, p.429).

Assim, Monbeig (1944b, p.430), a respeito do campo paulista, afirma que "as paisagens rurais atuais não revelam somente a revolução lenta e pacífica da agricultura e da sociedade rural; elas testemunham também uma melhor utilização dos solos", ou seja, a paisagem rural paulista não apresenta apenas a agricultura como base das atividades, mas sim uma transformação diferenciada do sul brasileiro com atividades semi-industriais.

Monbeig (1945a), numa análise da produção de cacau no espaço rural do sul da Bahia, faz uma caracterização do meio natural com o gênero de vida presente. $\mathrm{O}$ autor deixa claro seu método empregado nessa pesquisa:

No estado atual de nossos conhecimentos, o trabalho do geógrafo baseia-se essencialmente no estudo regional: só o desenvolvimento de semelhantes estudos permitiu que abrandassem os velhos princípios do determinismo ratzeliano. (MONBEIG, 1945a, p.1878). 
Monbeig (1945a) diz que para desenvolver um estudo regional, não se deve fundamentar em apenas um aspecto, seja ele humano ou natural. Deve-se ter um cuidado em não salientar uma característica, mas sim um entendimento de ambos:

Como o geógrafo parte de condições naturais, procura traçar um mapa de regiões naturais que não são precisamente unidades econômicas; e esse mapa não coincide com o dos gêneros de vida. Este exemplo é suficiente para mostrar a delicadeza com que todo geógrafo deve começar a delimitação da base territorial sobre a qual assentará o seu estudo, esforçando-se por não se restringir exclusivamente aos contornos geológicos, nem adotar uma zona econômica, nem ainda limitar-se a um agrupamento social. (MONBEIG, 1945a, p.1878).

Em outro estudo regional, Monbeig (1945b) viaja pelo norte paranaense relatando as características fisiográficas e humanas dessa região. Descreve a frente pioneira que ocupou o território, no sentido de conhecer as diferentes regiões do Brasil. As zonas pioneiras são temas bastante pesquisados pelo autor.

Em um estudo acerca dos diferentes gêneros de vida rurais no estado de São Paulo, Monbeig (1949) se esforçou para traçar uma classificação dos tipos de populações rurais. Nesse estudo regional da geografia humana, Monbeig dividiu em dois grandes gêneros de vida no estado de São Paulo, o fazendeiro e o caboclo, em que o primeiro é o "grande proprietário que pratica a agricultura comercial introduzida pelos europeus nas regiões tropicais. O segundo é o desbravador indígena, isolado na floresta, com suas culturas à base de queimadas, deslocando-se continuamente" $(1949$, p.980).

O artigo de Monbeig (1953) que trata da estrutura agrária no oeste paulista. Começa descrevendo as condições físicas dessa região. Entretanto, no decorrer do trabalho, nota-se uma mudança no texto do autor. Antes, os trabalhos eram detalhados com relação à descrição das paisagens e com os aspectos de habitat. Nesse artigo, o autor toca em assuntos como a condição jurídica da terra, migrações, estrutura fundiária e fragmentação das terras "A condição jurídica das terras, num Brasil que havia sido domínio português, trazia sérios obstáculos à colonização pioneira". (MONBEIG, 1953, p.457). O conceito de paisagem é bastante utilizado pelo autor, indicando o local habitado e com as transformações realizadas pelo homem:

A estrutura social do mundo pioneiro está impressa na paisagem: muito cheia de contrastes, é mais bem compreendida no terreno, o que não se dá nos campos muito alongados do nosso país. Contrasta a zona de sítios com a de fazendas. (MONGEIG, 1953, p.465).

Todavia, o caráter metodológico do autor centra-se na observação e no método indutivo. A descrição continua sendo a principal ferramenta de Monbeig, mas, nesse texto, o autor insere temas antes não abordados em sua produção científica. Entretanto, o autor deixa claro que uma análise mais aprofundada da situação da paisagem dessa frente pioneira seria feita somente através de um inquérito mais apurado.

Monbeig (1957) analisa as tendências da agricultura paulista, além de verificar os impactos do êxodo rural e suas conseqüências para a atividade agrícola.

Pierre Monbeig (1954) analisa a economia cafeeira no Brasil ao longo de sua trajetória do século XIX e XX, com análises estatísticas da produção, além de caracterizar os aspectos sociais e econômicos, situando no contexto do mundo atual:

A geografia econômica do café reflete perfeitamente o mundo atual: dela apreendemos aquilo que subsiste ainda de uma época em que os grandes países industrializados do hemisfério norte dominavam as economias e exploravam os recursos dos países tropicais. Mas, ao mesmo tempo, esta geografia permite medir os esforços dos países subdesenvolvidos para se libertarem ao preço de mil dificuldades. (MONBEIG, 1954, p.285). 
Analisando a produção de Monbeig, podemos fazer um esquema (figura 3) a respeito da abordagem e das perspectivas teórico-metodológicas da geografia francesa e de suas influências na geografia agrária brasileira.

\section{Abordagem teórico-metodológica francesa}

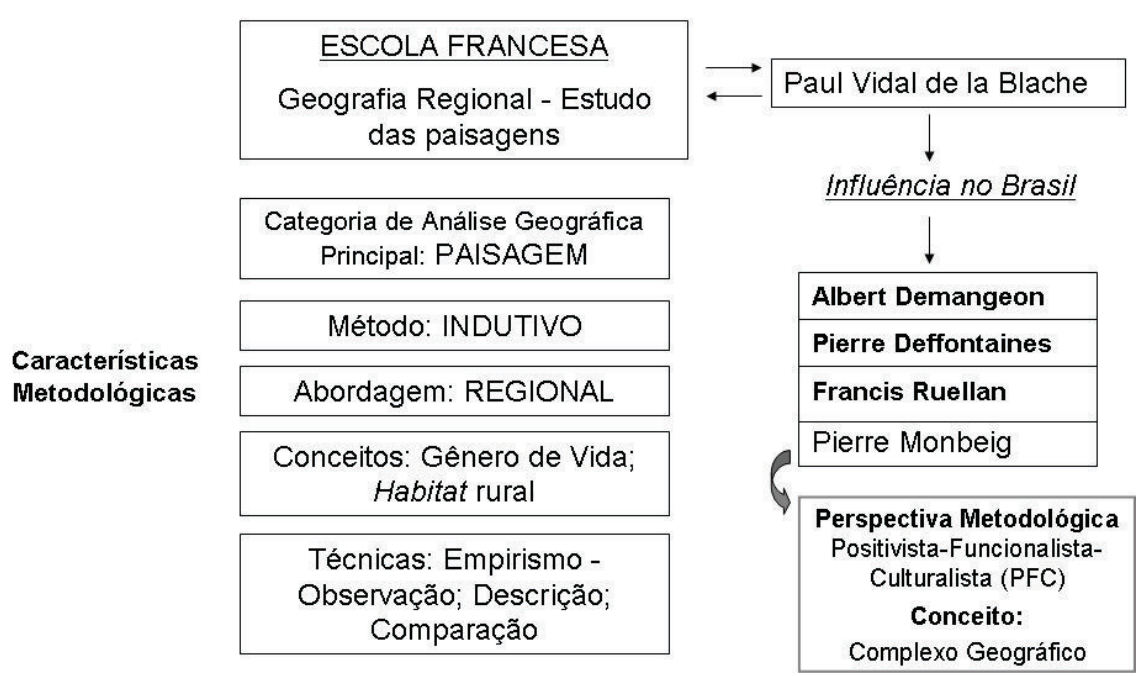

Figura 3 - Organograma 2: Abordagem teórico-metodológica da geografia francesa. Organização: Flamarion Dutra Alves

Os conceitos enfatizados na geografia agrária clássica estavam relacionados às organizações rurais, como o habitat, os gêneros e os modos de vida, os tipos de povoamento e o sistema agrícola. As influências teóricas e metodológicas francesas e alemãs embasaram as pesquisas no Brasil, por isso, o predomínio dos estudos regionais originários de Paul Vidal de La Blache que se difundiram com Pierre Monbeig ou os estudos das paisagens agrárias (econômicas e culturais) de Leo Waibel, que foi o grande mestre de Orlando Valverde.

\section{LEO WAIBEL: a geografia alemã nos estudos rurais brasileiros}

Em relação às influências exercidas e ao referencial deixado na geografia agrária brasileira, a escola alemã teve menor impacto na construção do pensamento geográfico comparado à escola francesa. Entretanto, o geógrafo Leo Heinrich Waibel (figura 4), nascido no dia 22 de fevereiro de 1888, vindo a falecer em 4 de setembro de 1951, durante seu período no Brasil, de 1946 a 1950, desenvolveu diversas pesquisas a cargo do Conselho Nacional de Geografia. Principalmente, acerca da colonização e do uso da terra pela agricultura em áreas de expansão, consideradas vazias em termos populacionais, como as regiões sul, centro-oeste e norte.

Sua produção bibliográfica no Brasil é dispersa em vários artigos publicados na Revista Brasileira de Geografia e Boletim Geográfico, além dos livros "A Colonização dos campos do Estado do Paraná" (1949) e "Capítulos de Geografia Tropical e do Brasil" (1958), entre muitas obras publicadas na Alemanha no período de 1912 a 1942.

As bases teórico-metodológicas que balizaram as pesquisas de Leo Waibel passaram, sem dúvida, pelos ensinamentos do geógrafo Alfred Hettner, ou seja, o entendimento da paisagem cultural e as formações econômicas das paisagens. Para Etges (2000a, p.15) Waibel desenvolveu quatro conceitos chave em sua obra "Paisagem Cultural, Formação Econômica, Colonização e Uso da Terra".

De forma resumida, a obra de Hettner se concentra em mostrar que o cerne metodológico da geografia é a abordagem corológica, ou seja, explicar e descrever as características diferenciadas 
da superfície terrestre. Para isso, as noções básicas da pesquisa para ele concentram-se sobre "a observação de campo, o aprofundamento teórico, através de leituras sistematizadas, coleta e sistematização de dados coletados, objetivando a generalização" (ETGES, 2000a, p.25).

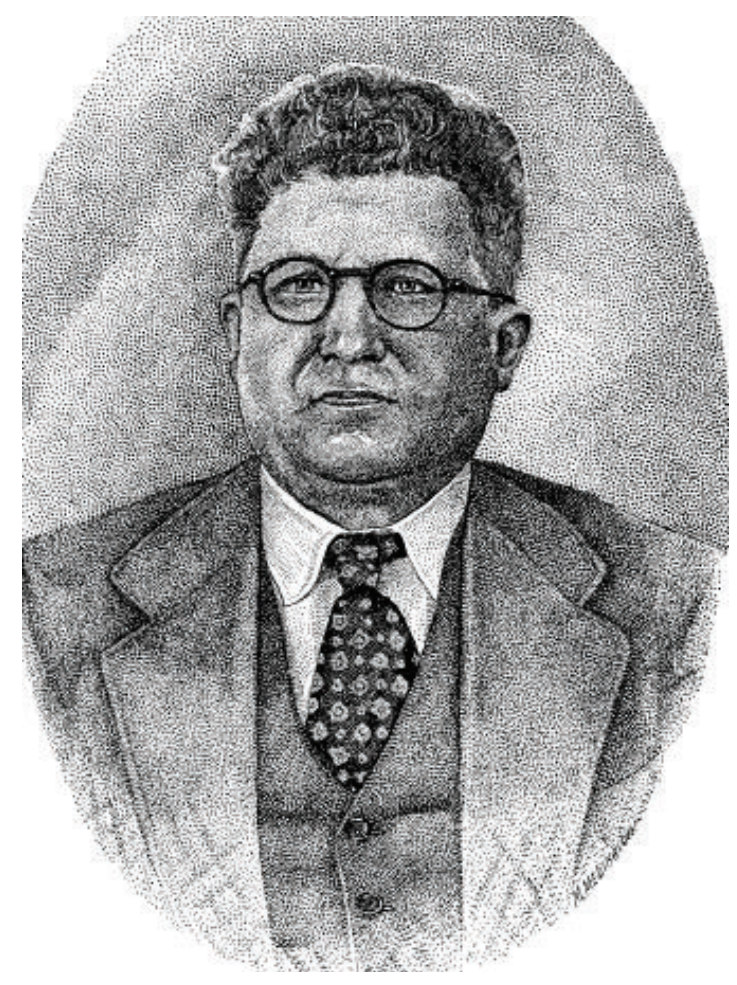

Figura 4 - Leo Waibel

Fonte: Bernardes (1952, p.201).

Leo Waibel, sob esta influência hetteneriana, inseriu novas técnicas e teorias no estudo da geografia agrária, dentre elas a dos economistas, neste caso a Teoria da Localização Agrícola de Von Thünen. Em seu livro publicado em 1933, "Problemas da Geografia Agrária", desenvolveu essa metodologia de análise, e posteriormente, em 1938, aplicou o modelo thuniano para explicar a organização dos produtos agrícolas nas regiões tropicais, em destaque a Guatemala e Costa Rica. Waibel conseguiu trazer para a geografia os fundamentos teórico-metodológicos do modelo espacial e locacional, essencialmente para os espaços agrários:

O "Estado Isolado" de Thünen demonstra ser a chave da geografia agrária. Ele nos possibilita discernir entre as causas intrínsecas inerentes à economia e atuantes na organização agrogeográfica da Terra e as causas referentes às condições naturais. $\mathrm{O}$ forte contraste entre as forças endógenas e exógenas torna-se claro na geografia econômica, e somos levados a tentar elucidar a sua influência na individualização das paisagens econômicas da Terra. (WAIBEL, 1955b, p.294.).

Em seu trabalho sobre as áreas de produção agrícola e pecuária na Costa Rica, Waibel (1948) utilizou o modelo do Estado Isolado de Von Thünen como ferramenta metodológica para entender a organização das populações, levando em consideração os aspectos naturais, atividades agropecuárias e o distanciamento das cidades.

Com influências de Alfred Hettner (sua base principal) e Ritter e Ratzel, com menos ênfase, sua base metodológica aponta para uma classificação das diferentes paisagens agrárias levando em conta os dados Estatísticos, Ecológicos e Fisionômicos. Esses elementos determinam uma paisagem agrária (figura 5), o que entendemos hoje por espaço rural. Este assunto é lembrado por Etges (2000a, p.51): 
Waibel, sem sombra de dúvida, percorreu a mesma trajetória dos geógrafos que se queriam fazer respeitar como cientista na época: começa nas ciências naturais, estudando o mundo das plantas e dos animais, na tradição de Humboldt, para num segundo momento, tomar consciência da importância do papel da História e do homem, consequentemente, na configuração das paisagens, na tradição de Ritter. Introduziu o econômico nas suas análises (Wirtschaftsformation) e passou a analisar as paisagens como paisagens culturais, na tradição de Schlüter e Hettner. (ETGES, 2000a, p.51).

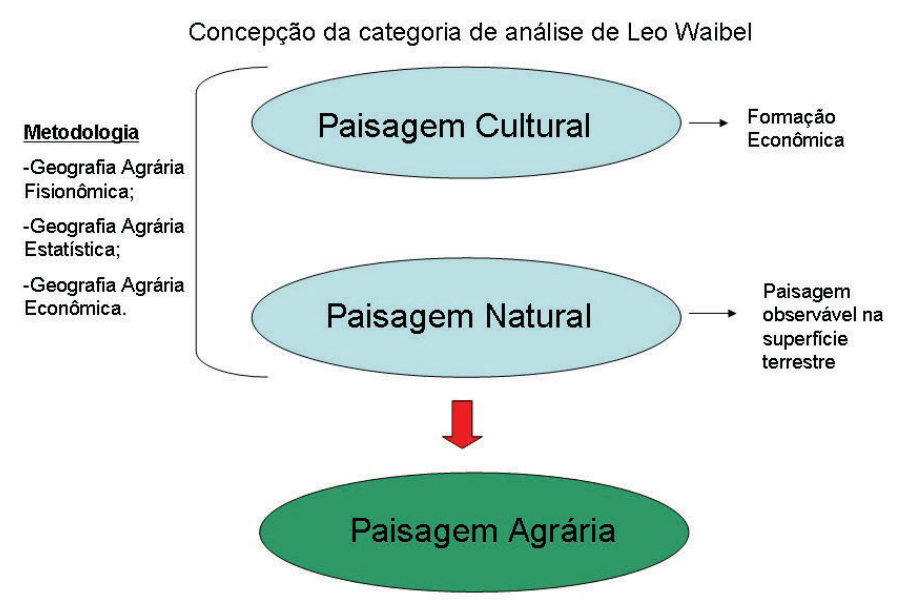

Figura 5 - A categoria Paisagem Agrária na obra de Leo Waibel.

Fonte: ALVES \& MAIA (2009, p.16)

Waibel teve muita influência da geografia econômica no desenvolvimento de seus estudos da paisagem agrária, desprendendo-se do determinismo alemão que considerava e valoriza os aspectos físicos sobre o homem:

[...] Waibel passou a orientar-se para análises sistemáticas no campo da Geografia Econômica, especialmente no que dizia respeito ao espaço agrário. Nas discussões referentes à Geografia da Paisagem (Landschaftskunde) Waibel deu a sua contribuição quando passou a destacar o papel dos homens na formação da paisagem cultural, conceito este que tem sua origem nas pesquisas sobre a paisagem do início do século XX, expressando a influência dos homens na formação e transformação da superfície terrestre. (ETGES, 2000b, p.40).

Schneider (2002) trata o conceito de paisagem cultural utilizado por Waibel como uma possibilidade nos estudos e reflexões na inter-relação entre o espaço rural e urbano:

[...] parece sugestivo o conceito de paisagem cultural, que poderá constituir-se em ferramenta analítica interessante para auxiliar na reflexão acerca das inter-relações espaciais entre o rural e o urbano, cujas fronteiras são cada vez mais difíceis de serem delimitadas. A superação desta dicotomia, de corte setorial (do tipo agrícola versus indústria) e não raramente embebida de conteúdo ideológico (no sentido de comparar o atrasado versus o moderno), poderá ser o primeiro passo para se pensar a dinâmica sócio-espacial do meio rural em sentido mais amplo que aquele relacionado aos atributos produtivos e comerciais das atividades econômicas que ali são predominantes. (SCHNEIDER, 2002, p.40).

Verdum (2005) ao discorrer sobre a importância de alguns geógrafos que trabalham com as transformações no espaço geográfico decorrentes da modernização, ele cita a contribuição de Leo Waibel: "através da abordagem considerada como sendo a da paisagem cultural, esses geógrafos são, na sua maioria, testemunhas vivas das opções de desenvolvimento rural brasileiro e das degradações ambientais" (2005, p.92).

Dessa forma, o papel desempenhado por Waibel foi de significativa importância para a geografia agrária, superando o determinismo geográfico associando o cultural na formação da paisagem agrária - a paisagem cultural. Conceito este que pode ser utilizado proficuamente nos estudos sobre 
a relação cidade campo, conforme referido por Schneider (2002), uma vez que Waibel vai introduzir na análise espacial (figura 6), além das análises da forma e função contidas nos modelos de Von Thünen, a questão da estrutura sócio-cultural influenciando esse espaço específico.

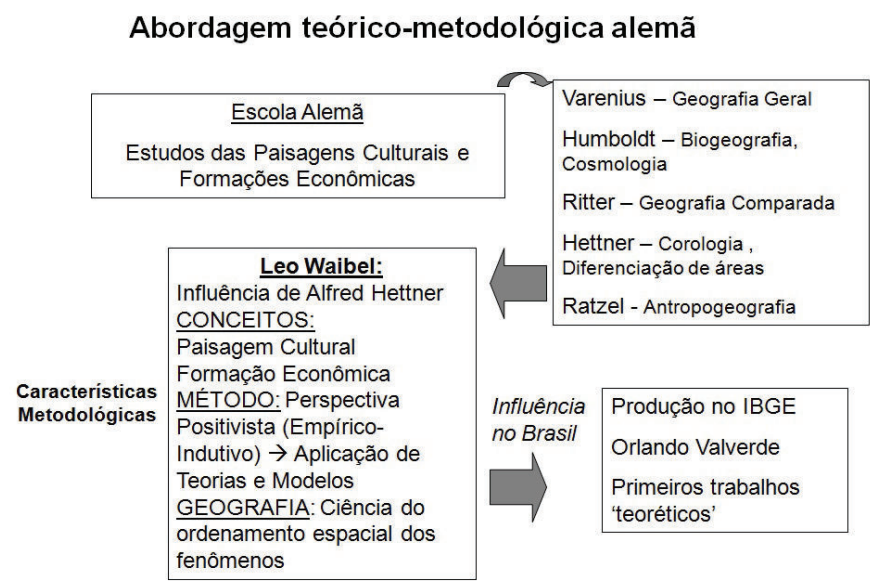

Figura 6 - Organograma 3 : Abordagem teórico-metodológica da geografia alemã e de Leo Waibel. Organização: Flamarion Dutra Alves

As influências deixadas por Leo Waibel para a geografia agrária brasileira passam, sem dúvida, nos trabalhos desenvolvidos no IBGE, e na formação de pesquisadores nesse instituto. Entre eles, destaca-se Orlando Valverde, que seguiu a linha metodológica de Waibel. A utilização de teorias e modelos foram inovações no campo da geografia agrária, Leo Waibel, ao usar Von Thünen, fugiu das simples observações e descrições das paisagens. Ele fazia essa descrição, contudo correlacionava as paisagens naturais com as culturais com uma ligação histórica, para assim identificar e classificar as diferentes áreas.

O acréscimo teórico-metodológico da obra de Waibel surge em 1923, quando ocupou a cátedra no Instituo de Kiel, onde desenvolveu diversos trabalhos de geografia econômica, especificamente a geografia agrícola. Entretanto, as viagens de campo foram de suma importância para o enriquecimento do conhecimento geográfico aplicado de Waibel (Quadro 1),

O período de cinco anos que ficou no Brasil é considerado o mais profícuo da carreira cientifica de Waibel. Foi nas áreas de colonização e de expansão da agricultura que ele, juntamente com outros geógrafos do IBGE, Fábio de Macedo Soares Guimarães, Orlando Valverde, Walter Alberto Egler, Nilo Bernardes e Speridião Faissol desenvolveram as pesquisas sobre as novas áreas ocupadas no território nacional, sob a política governamental do Estado Novo de Getúlio Vargas. (ALMEIDA, 2003).

Quadro 1 - Viagens científicas de Leo Waibel

\begin{tabular}{|l|l|}
\hline \multicolumn{1}{|c|}{ PERÍODO } & \multicolumn{1}{c|}{ DESTINO } \\
\hline $1911-1912$ & Camarões \\
\hline 1914 & Sudoeste Africano (Colônias alemãs) \\
\hline $1925-1926$ & México e Estados Unidos \\
\hline 1937 & América Central \\
\hline 1939 & Estados Unidos \\
\hline $1946-1950$ & Brasil \\
\hline
\end{tabular}

Fonte: Bernardes (1952)

Organização: Flamarion Dutra Alves. 


\section{Temas estudados por Leo Waibel}

Durante sua vida acadêmica e profissional, Waibel preferiu trabalhar com temáticas relacionadas com a agricultura e as populações rurais. Desta maneira, os conceitos enfatizados na geografia agrária clássica remetiam às organizações rurais, como o habitat, os gêneros e os modos de vida, os tipos de povoamento e o sistema agrícola. Os estudos regionais para conhecer novas áreas a partir da colonização formaram boa parte dos trabalhos de Waibel.

A metodologia de Waibel era calcada na análise da Geografia Agrária Estatística, Fisionômica e Ecológica com a aplicação de teorias e modelos espaciais, principalmente a Teoria da Localização da Produção Agrícola.

Waibel (1947a) retratou a economia agrícola da região dos trópicos, fazendo uma caracterização geral da produção e a relação com as condições climáticas e a industrialização. Para tal, analisou os países asiáticos, africanos e latino-americanos. A ideia dessas pesquisas era de "desvendar" as diferentes regiões, ou seja, conhecer os diferentes modos de vida e como se organizavam. Assim, Waibel (1948a) trabalhou com a Teoria do Estado Isolado de Von Thünen na espacialização das culturas agrícolas na Costa Rica (figura 7).

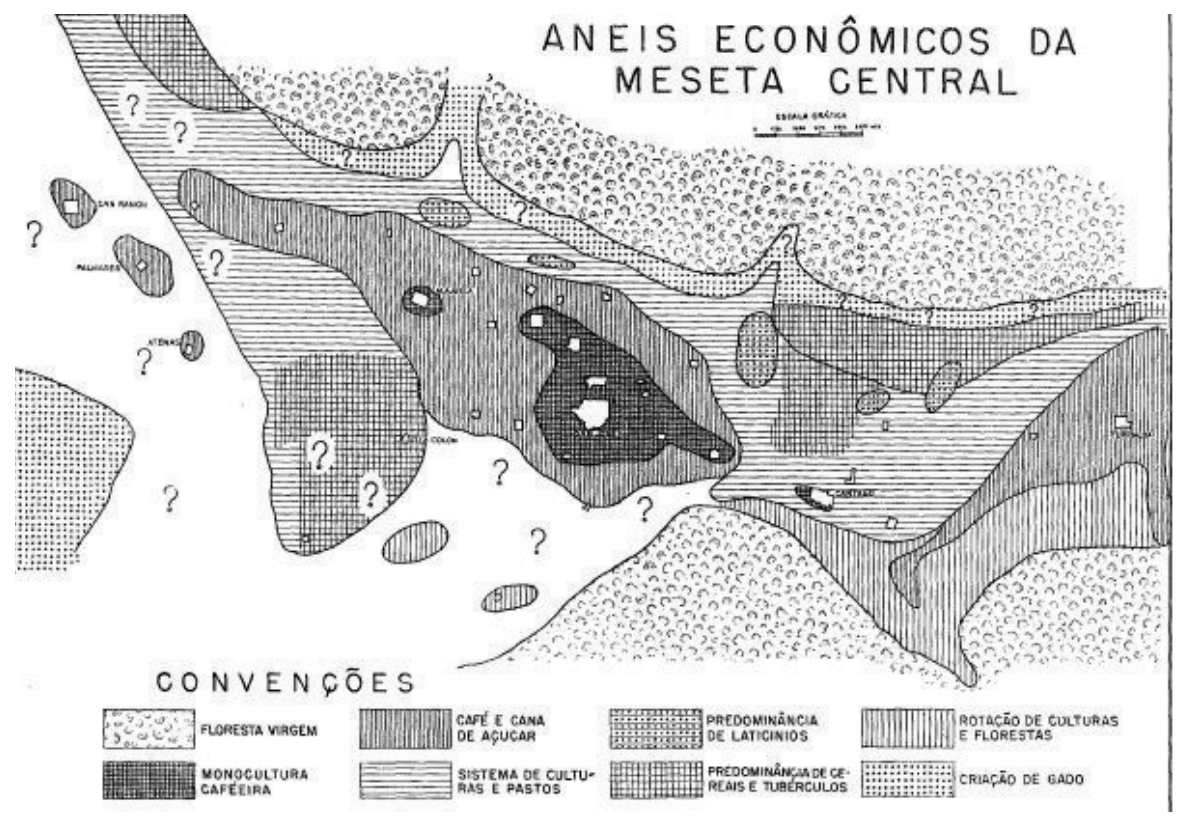

Figura 7 - Uso da Teoria de Von Thünen na região central da Costa Rica.

Fonte: Waibel (1948a, p.20).

Este estudo deu início a outras metodologias para a geografia agrária, enfocando o caráter espacial e, ao mesmo tempo, relacionando com os elementos econômicos, que são importantes para a agricultura e as populações rurais. Dessa forma, a geografia agrária deixou de ser meramente descritiva e passou a ser um ramo conexo com a geografia econômica, industrial, do comércio, assim, fazendo inter-relações com elementos que interferem na economia de determinada localidade.

Entretanto, esse modelo aplicado por Waibel na Costa Rica não é estático e isolado, como o modelo proposto por Thünen, as dinâmicas da região, a população e o relevo acidentado não permitem compor anéis concêntricos. Mas a base teórica e metodológica serve como parâmetro desse novo estudo regional.

A respeito da Teoria do Estado Isolado de Von Thünen na geografia agrária, Leo Waibel (1955b) tece algumas considerações sobre o método e a aplicabilidade da teoria. Primeiramente, ele discute sobre qual filosofia pertence o método de Thünen:

Indiscutivelmente, a favor do método indutivo depõe, em todo caso, a preferência de Thünen pelo emprego dos métodos matemático-algébricos, que se tornam para ele uma verdadeira paixão, sendo 
empregados inclusive onde não são necessários. Isto dificulta sobremaneira a leitura de sua obra e em parte é uma das causas que contribuíram para a sua pouca divulgação. Dedutiva é também a sua concepção da abstração, "que ele manuseia com grande virtuosidade e que lembra inteiramente o processo de trabalho do pesquisador experimental em ciências naturais. [...] O fundamental no método de Thünen é, portanto, que ele pesquisou e raciocinou tanto de modo dedutivo como indutivo. (WAIBEL, 1955b, p.277).

Como bases teóricas de Leo Waibel, destacam-se Carl Ritter e Alfred Hettner delineando um pensamento naturalista da formação da paisagem. Todavia, através da teoria de Von Thünen, Waibel conseguiu trazer para a geografia os fundamentos teórico-metodológicos do modelo espacial e locacional, essencialmente para os espaços agrários:

O "Estado Isolado" de Thünen demonstra ser a chave da geografia agrária. Ele nos possibilita discernir entre as causas intrínsecas inerentes à economia e atuantes na organização agrogeográfica da Terra e as causas referentes às condições naturais. $O$ forte contraste entre as forças endógenas e exógenas torna-se claro na geografia econômica, e somos levados a tentar elucidar a sua influência na individualização das paisagens econômicas da Terra. (WAIBEL, 1955b, p.294).

O Sul de Goiás foi estudado em sua pesquisa publicada em 1947. Nesta região, Waibel (1947b) mostrou como as colônias agrícolas viviam e produziam, além de caracterizar o tamanho das propriedades e as origens da população residente, ou seja, uma pesquisa que visava conhecer o imenso território brasileiro, através de caracterização das áreas de colonização. A respeito da colonização europeia no Sul brasileiro, Waibel (1949) faz uma síntese das viagens realizadas nos três Estados que compõem essa região. Primeiramente, ele deixa clara a forma de entender a paisagem geográfica:

O nosso modo de encarar o problema da colonização será do ponto de vista geográfico, salientando as relações entre a terra de um lado e as atividades do colono de outro. A paisagem cultural criada pelo colono é o nosso tema principal. Os outros aspectos da colonização, tais como a história e as condições jurídicas, religiosas, sociais e políticas, serão mencionadas somente na medida que estiverem relacionadas com a paisagem cultural. (WAIBEL, 1949, p.160).

Neste trabalho, Waibel descreve as condições naturais da região, explicando como é a base física que dá suporte aos sistemas agrícolas ali existentes. Mostra também os tipos de colonizações e as origens dos imigrantes (alemães, italianos e eslavos). Essa combinação entre colonização e sistema agrícola está diretamente relacionada à construção da paisagem cultural, pois o tipo de atividade agrícola desenvolvida representa uma parte dessa paisagem:

Depois do tipo de colonização, é o sistema agrícola adotado pelos colonos o fato de maior significado para a colonização. Estas coisas são, muitas vezes, consideradas como evidentes por si próprios e de pouco interesse científico. Contudo, os sistemas agrícolas são na realidade muito complicados e envolvem muitos problemas. Constituem os objetos de duas ciências que parecem mal conhecidas no Brasil, a economia agrícola e a geografia agrícola. (WAIBEL, 1949, p. 180).

Waibel (1949) distingue três tipos de sistemas agrícolas, nos quais entende como um processo evolutivo da paisagem cultural: 1) sistema da primitiva rotação de terras; 2) sistema de rotação de terras melhorada; e 3) rotação de culturas combinadas com a criação de gado. Em relação aos tipos de povoamento, o autor descreve os habitat rurais e os núcleos de população, e na visão dele os imigrantes devem morar em núcleos homogêneos, não havendo muito contato com os "luso-brasileiros". Essa ideia proposta pelo alemão Leo Waibel não confere com os ideais nacionalistas do Governo brasileiro de formar uma nação. Os núcleos "fechados" de colonos mantinham pouco contato com os brasileiros, além de manter a língua do país de origem. 
Waibel (1954) pesquisou uma das formas de ocupação do espaço agrícola nas regiões tropicais, o "Plantage", sendo um local de atividade intensa e de monocultura. Conforme as bases teóricas de Waibel, o autor considera paisagem como a categoria da análise na geografia agrária, e sobre estes temas ele afirma:

Este contraste fisionômico da paisagem entre os estabelecimentos nativos e os estabelecimentos do tipo "plantage", até as primitivas condições de vida da população nativa sofreram fundamentais transformações na sua estrutura social, econômica e política por influência dos europeus. (WAIBEL, 1954, p.370).

Waibel (1954, p.376) define o "Plantage" da seguinte forma: "uma "plantage" é um grande estabelecimento agroindustrial, que via de regra, sob direção de europeus produz, com grande emprego de trabalho e de capital, produtos agrícolas valorizados para o mercado mundial”. Assim, o autor considera esse tipo de cultura agrícola voltada para o mercado externo, alterando a paisagem cultural típica das regiões tropicais nesse aspecto teórico. Waibel (1955a) verifica essa produção de "plantage" nas zonas tropicais com as áreas de colonização realizadas pelos europeus, analisando a questão do abastecimento do mercado europeu.

Waibel (1955c) estudou as "zonas pioneiras" criadas pela expansão da agricultura no Brasil, analisando os principais impactos decorrentes da criação dos novos povoamentos na paisagem agrária e urbana. Destaca as zonas pioneiras desde o século XVIII, com a cultura do algodão no Maranhão, e posteriormente, no século XIX, o desenvolvimento da cultura do café sendo o principal produto para a criação dessas zonas pioneiras no Brasil Central, em especial, o Estado de São Paulo. Além dessas regiões, o Sul do Brasil também teve suas zonas pioneiras nesse mesmo século, com as colônias de imigrantes europeus. No século XX, as zonas pioneiras destacadas por Waibel (1955c) concentram-se no Centro-Oeste e na região Sul, mais ao norte do Paraná, com o desenvolvimento do café, e ao oeste da região Sul. Após estas constatações realizadas através de trabalhos de campo, Waibel (1955c) faz algumas comparações entre as zonas pioneiras e a agricultura no Brasil e dos Estados Unidos.

Apesar de sua breve passagem pelo Brasil, Waibel conseguiu estudar e caracterizar diferentes regiões, ainda pouco conhecidas, principalmente, os assuntos ligados à agricultura, à população e à economia. Além disso, inseriu na geografia agrária novas formas de pesquisa, ao aplicar teorias econômicas nos procedimentos metodológicos e fazer análises com uma gama de variáveis.

\section{CONSIDERAÇÕES FINAIS}

Ao resgatar a história da geografia agrária, buscou-se analisar autores e escolas que deram sua contribuição à pesquisa geográfica sobre as questões ligadas ao rural e aos legados deixados para a epistemologia da geografia.

Os pressupostos teórico-metodológicos da escola francesa tiveram maior influência na geografia brasileira, bem como nos estudos rurais. A herança deixada por esta vertente teórica, pela sua figura maior, Pierre Monbeig, e na formação de diversos pesquisadores e linhas de pesquisas sobre a geografia regional.

Assim, o estudo regional foi, sem dúvida, a grande herança deixada pelos geógrafos franceses que passaram pelo Brasil, entre eles Pierre Monbeig, que formaram o lastro da geografia brasileira. Em paralelo, a geografia alemã, por sua vez, analisada na figura de Leo Waibel destaca-se pela influência deixada no IBGE e nos pesquisadores que trabalharam nesta época.

Como a formação dos cursos universitários no Brasil se deu pela vinda dos geógrafos franceses, o referencial teórico alemão não teve o mesmo grau de aplicabilidade no início da geografia universitária no Brasil. Devido ao convite do IBGE para que alguns geógrafos alemães exercessem pesquisas no Brasil, foi nesse momento que houve uma maior integração dessa base teórico-meto- 
dológica. Os elementos econômicos e culturais da paisagem remetem a um avanço das descrições da paisagem, além da contribuição estatística e modelística para o entendimento da organização do espaço, dando os primeiros indícios de uma geografia teorética.

\section{REFERÊNCIA BIBLIOGRÁFICA}

AB'SÁBER, Aziz Nacib. Pierre Monbeig: a herança intelectual de um geógrafo. p.221-232. Estudos Avançados, v.8, n.22, 1994.

ALMEIDA, Roberto Schmidt de. A Geografia do IBGE: Um Esboço Histórico. Revista do Instituto Histórico e Geográfico Brasileiro, v. 164, n. 418, 2003. p. 79-99.

ALVES, Flamarion Dutra. A influência alemã e francesa na geografia agrária brasileira. p.2000-2016. In: IX Seminário de Pós-Graduação em Geografia da UNESP Rio Claro. Anais... Rio Claro: AGETEO, 2009.

ALVES, Flamarion Dutra; FERREIRA, Enéas Rente. Elementos metodológicos da geografia agrária clássica: a produção em periódicos brasileiros. p.43-61. GeoUERJ, v.2, n.18, 2008.

ALVES, Flamarion Dutra; MAIA, Adriano Corrêa. Teorias sobre o espaço e a questão rural-urbano. $2^{\circ}$ Simpósio O rural e O urbano no Brasil. Anais... Rio de Janeiro, 2009. p.1 -27.

ANDRADE, Manuel Correia de. A construção da geografia brasileira. p.21-30. Finisterra, XXXIV, 67-68, 1999.

BERNARDES, Nilo. Leo Waibel. p.199-201. Revista Brasileira de Geografia, v.14, n.2, 1952.

BRAY, Silvio Carlos. Considerações sobre o método de interpretação funcionalista na geografia. Boletim de Geografia Teorética. v.10, n.20, 1980. p.33-43.

BRAY, Silvio Carlos. Pierre Monbeig, o patriarca da geografia paulista e nacional. In: Geografia, v.12, out., n.24, 1987. p.119-120.

BRAY, Silvio Carlos. A geografia acadêmica tradicional no Brasil: positivismo com historicismo? I Colóquio Brasileiro de História do Pensamento Geográfico. Anais... Uberlândia, 2008. p.1-8.

DANTAS, Aldo. Monbeig: paisagem e geografia estigmática. Mercator, v.1, n.2, 2002. p.71-78.

DANTAS, Aldo. Pierre Monbeig: um marco da geografia brasileira. Porto Alegre: Sulina, 2005.

ETGES, Virgínia Elisabeta. Geografia Agrária: a contribuição de Leo Waibel. Santa Cruz do Sul: EDUNISC, 2000a.

ETGES, Virgínia Elisabeta. A paisagem agrária na obra de Leo Waibel. GEOgraphia, n.4, ano 2. Niterói, 2000b. p.27-47.

MONBEIG, Pierre. Estudos Geográficos. Boletim Geográfico. v.1, n.11, 1944a. p.7-11.

MONBEIG, Pierre. Notas relativas à evolução das paisagens rurais no Estado de São Paulo. Boletim Geográfico, v.2, n.16, 1944b. p.428-430.

MONBEIG, Pierre. Os problemas geográficos do cacau no sul do Estado da Bahia. Boletim Geográfico, v.2, n.24, 1945a. p.1878-1883.

MONBEIG, Pierre. A zona pioneira do Norte-Paraná. Boletim Geográfico, v.3, n.25, 1945b. p.11-17.

MONBEIG, Pierre. A Geografia no ensino secundário. Boletim Geográfico, V.3, n.26, 1945c. p.163-171.

MONBEIG, Pierre. Pesquisas Geográficas. Boletim Geográfico, v.3, n.31, 1945d. p.915-919.

MONBEIG, Pierre. A geografia e o meio vivo. Boletim Geográfico, v.3, n.34, 1946. p.1267-1269.

MONBEIG, Pierre. Evolução de gêneros de vida rurais tradicionais no sudeste do Brasil. Boletim Geográfico, v.7, n.81, 1949. p.980-987.

MONBEIG, Pierre. As estruturas agrárias da faixa pioneira paulista. Boletim Geográfico, v.11, n.116, 1953. p. 455-465.

MONBEIG, Pierre. Resumo da geografia econômica do café. Boletim Geográfico, v.12, n.122, 1954. p. 276-287.

MONBEIG, Pierre. As tendências atuais da agricultura no Estado de São Paulo. Boletim Geográfico, v.15, n.141, 1957. p. 721-726. 
SCHNEIDER, Sergio. A atualidade da contribuição Leo Waibel ao estudo da agricultura familiar. Boletim Gaúcho de Geografia, v. 28, n. 1, 2002. p. 25-41.

VERDUM, Roberto. Os geógrafos frente às dinâmicas sócio-ambientais no Brasil. Revista do Departamento de Geografia, n.16, São Paulo, 2005. p.91-94.

WAIBEL, Leo. O sistema das plantações tropicais. Boletim Geográfico, v.5, n.56, 1947a. p.896-900.

WAIBEL, Leo. Uma viagem de reconhecimento ao sul de Goiás. Revista Brasileira de Geografia, v.9, n.3, 1947b. p. 313-342.

WAIBEL, Leo. A teoria de Von Thünen sobre a influência da distância do mercado relativamente a utilização da terra. Revista Brasileira de Geografia, v.10, n.1, 1948a. p.3-40.

WAIBEL, Leo. Vegetação e o uso da terra no Planalto Central. Revista Brasileira de Geografia, v.10, n.3, 1948b. p.335-380.

WAIBEL, Leo. Princípios de colonização européia no Sul do Brasil. Revista Brasileira de Geografia, v.11, n.2, 1949. p.159-222.

WAIBEL, Leo. A forma econômica da "Plantage" tropical. Boletim Geográfico, v.12, n.123, 1954. p.369-383.

WAIBEL, Leo. O abastecimento da zona temperada com produtos agrícolas tropicais. Boletim Geográfico, v.13, n.125, 1955a. p.143-154.

WAIBEL, Leo. A lei de Thünen e a sua significação para a geografia agrária. Boletim Geográfico, v.13, n.126, 1955b. p.273-294.

WAIBEL, Leo. As Zonas Pioneiras do Brasil. p.389-422. Revista Brasileira de Geografia, v.17, n.4, 1955c. WAIBEL, Leo. Capítulos de Geografia Tropical e do Brasil. Rio de Janeiro: IBGE, 1958.

WAIBEL, Leo. Determinismo geográfico e geopolítica. Boletim Geográfico, n.19, v.164, 1961. p.612-617.

Trabalho enviado em maio de 2011 Trabalho aceito em agosto de 2011 